\title{
LOS TRATAMIENTOS DE LIBERALISMO EN LA OBRA DE MANUEL GONZÁLEZ PRADA
}

\author{
Universidad de Bucarest \\ Rumanía \\ aura.bunoro@lls.unibuc.ro
}

Aura Cristina Bunoro

doi.org/10.15452/SR.2020.20.0001

Resumen. La palabra «libertad» significa facultad natural que tiene el hombre de obrar, estado o condición de quien no es esclavo, privilegio, etc. «Hablo, señores, de la libertad para todos» es una frase usada por Manuel González Prada en su discurso de 1888 al hablar sobre la cuestión indígena, cuestión que el autor presenta como un problema estructural; al mismo tiempo relaciona la libertad con el progreso de su país. El autor de Horas de lucha utiliza la palabra «libertad» tanto para referirse al estado independiente del país después del final del período colonial, a la situación de la población natural del país, pero también a la necesidad de una mente libre de los políticos en cuyas manos estaba el buen funcionamiento del Perú y de sus habitantes en su totalidad. Y, sobre todo, a cómo se relaciona la libertad con las raíces de un pueblo en búsqueda de su identidad nacional. La necesidad de independizar el Perú implicaba también libertad en el pensamiento de aquellos capaces de cambiar el rumbo del país hacia una nación que integrara a todos los ciudadanos y ofrecer derechos iguales para toda la población. Manuel González Prada mostró una preocupación tenaz por los derechos humanos, sobre todo por la libertad y la justicia. Según sus obras, la mayoría de las veces, las víctimas de las decisiones políticas y de las iniquidades cometidas por las autoridades eran los indígenas. La falta de derechos y de dignidad llevaba a la supresión de cualquier sentimiento nacional. El artículo «Nuestros indios» denuncia la explotación de la población indígena y la difícil situación en la que esta se hallaba por culpa del maltrato recibido después de la Conquista y durante el período colonial, causado por la falta de acceso a educación y por falta de libertades. En las Baladas peruanas de Manuel González Prada se pueden hallar también referencias a la manera de ser de los incas, a su valentía, a su inocencia, a su deseo de libertad y también a la forma de vestirse. La importancia de la libertad llevaba a veces a los incas a sacrificios supremos. En la balada «El cacique filicida» el autor relata la historia de un padre que prefirió matar a su hijo en vez de dejarlo vivir una vida en esclavitud o trabajando sin cesar en las minas. En Nuevas páginas libres González Prada utiliza el símbolo del cóndor para hacer referencia a las batallas de Junín y Ayacucho y presenta una posible alternativa en el caso en que el Perú no hubiera obtenido su independencia, alternativa que suponía la falta de libertad para la población indígena. 
Palabras clave. Libertad. Identidad nacional. Indígenas. Raíces.

\begin{abstract}
Meanings of the Word "Freedom" in Manuel González Prada's Work. The word "freedom" designs a natural faculty that a person has for acting, a state or a condition of a person who is not a slave, a privilege, etc. "Hablo, señores, de la libertad para todos" is a phrase used by Manuel González Prada in his speech in 1888, when talking about the condition of the indigenous people, that the author presents as a structural problem. At the same time, he relates freedom with the progress of his country. The author of Horas de lucha also uses the word "freedom" to refer to the independent state of the country after the end of the colonial period, to the situation of the indigenous people of the country, but also to the need of a free mind of the politicians who controlled the proper functioning of Peru and its citizens. Freedom is related with the roots of a nation searching for its national identity. The need to gain the independence of Peru also involved the liberty of thinking of those who were able to change the direction of the country towards a nation that would include all the citizens and offer equal rights for all the people. Manuel González Prada showed a tenacious concern for human rights, in particular, for liberty and justice. According to his writings, most of the times, the victims of political decisions and wrongdoings of the authorities included the indigenous people. The lack of rights and dignity lead to the deletion of any national feeling. The article "Nuestros indios" denounces the exploitation of the indigenous population and its difficult situation, because of the mistreatment received after the Conquista and during the colonial period, caused by the lack of access to education and lack of liberties. In Baladas peruanas, it is also possible to detect references to the way of life of the Incas, to their courage, to their innocence, to their wish for freedom, and to their way of dressing. The importance of freedom leads sometimes to supreme sacrifice. In the ballad "El cacique filicida", the author presents the history of a father who preferred to kill his son rather than let him live in slavery or work without rest in mines. In Nuevas páginas libres, González Prada uses the symbol of the eagle to refer to the battles of Junín and Ayacucho and shows what would have happened if Peru had not obtained its independence, having the lack of freedom of the indigenous people as its consequence.
\end{abstract}

Keywords. Freedom. National identity. Indigenous. Roots. 


\section{Introducción}

Conviene empezar este trabajo con una pregunta: ¿qué entendemos por libertad en el caso de González Prada? ¿La ruptura con los «viejos»? Es decir, la liberación de lo anterior (modo de pensar, literatura escrita hasta ese momento). ¿La lucha por los derechos de los indígenas? ¿La necesidad de romper con las lacras del periodo colonial prolongadas hasta la República? A continuación, observaremos que se pueden entender todas las ideas mencionadas anteriormente y mucho más.

En cuanto a la ruptura con los «viejos», «Los viejos a la tumba, los jóvenes a la obra» es una frase pronunciada en el discurso del Politeama en 1888. En una entrevista en la radio, el crítico literario Luis Alberto Sánchez, uno de los más importantes biógrafos de González Prada, explicaba qué entendía el autor por viejos: no se refería a la edad sino a los viejos del espíritu, a los que no eran capaces de librarse de sus vicios, a los intrigantes, a los que traicionaban a sus amigos por su propio bienestar. Los jóvenes eran todo lo contrario: los que manifestaban lealtad, capacidad de empresa, estímulo. Esta frase nos lleva hacia Ricardo Palma y la relación de cercanía-lejanía entre González Prada y el tradicionista. Con respecto a la lucha por los derechos de los indígenas, el autor de Páginas libres denunció el abuso hacia la población indígena y el maltrato recibido después de la Conquista y durante el período colonial, la falta de acceso a educación y la falta de libertades. Desde su punto de vista, incluso después de la obtención de la independencia, la población indígena seguía siendo desposeída de privilegios y esto se debía a la prolongación de las deficiencias del sistema colonial.

\section{Manuel González Prada y Ricardo Palma}

Raúl Porras Barrenechea, insigne historiador y diplomático peruano, al comparar a Ricardo Palma con el autor de Páginas libres, afirmaba que: «de ambos metales, del culto y el respeto del pasado y de la esperanza del porvenir se forma el alma nacional de un pueblo. En ese sentido fueron tan peruanos el uno como el otro» (Porras Barrenechea, 1969: 71).

Sobre el distanciamiento entre estos dos grandes escritores han escrito desde críticos contemporáneos coetáneos a ambos hasta críticos literarios de este siglo. En la primera categoría entra Abraham Valdelomar, quien plantea que la rivalidad entre el tradicionista y González Prada sigue alimentando discusiones $\mathrm{y}$ «transciende el periplo vital de los protagonistas» (Pinto G., 1985: 77).

Luis Alberto Sánchez analiza las hostilidades entre los dos grandes literatos y sostiene que estas empiezan desde la fundación del Círculo Literario, en 1885, «institución de escritores jóvenes y excombatientes de la guerra» (Sánchez, 1976: 25), que se oponía al Club Literario cuyo miembro fue también González Prada hasta 1878. Desde el punto de vista de Luis Alberto Sánchez, el hecho de que el tradicionista fuera secretario del presidente Balta mientras Piérola era ministro de Hacienda llevó a la enemistad entre González Prada y Palma (Sánchez, 1976: 26-27). Después siguieron los discursos del Politeama y del Olimpo en los que el autor de Páginas libres «denuncia las deficiencias y lacras» (Sánchez, 1976: 18) de la vida social del Perú y de las letras peruanas y la necesidad de librarse de los antiguos modelos. La frase célebre pronunciada en el discurso del teatro Politeama de Lima «Los viejos a la tumba, los jóvenes a la obra» supuso una ruptura entre la generación del tradicionista y la de González Prada. En una entrevista a José Carlos Mariátegui, González Prada afirmaba que la literatura de la generación anterior «se inspiraba en el romanticismo español» y le faltaban las ideas y las impresiones que pudieran reflejar «el momento de la civilización en que se produjo» (Mariátegui, 1985: 61). 
Otra faceta del conflicto entre Palma y González Prada está representada por la injusta anexión del tradicionista al colonialismo. El hecho de que a Palma se le considerara como un autor que había loado «sin reticencias al Coloniaje» (Sánchez, 1976: 28) y que González Prada estuviera en contra del ayer fueron otros motivos que profundizaron la aversión entre los dos. En relación a esta problemática, José Carlos Mariátegui es uno de los críticos que acercó, desde nuestro punto de vista, a Ricardo Palma y a González Prada. El tradicionista criticó vehementemente las acciones crueles de aquellos conquistadores que estaban obsesionados por las riquezas de los incas, así como los abusos del período colonial: «Ninguna institución u hombre de la Colonia y aun de la República escapó a la mordedura tantas veces tan certera de la ironía, el sarcasmo y siempre el ridículo de la jocosa crítica de Palma. [...] Se verá entonces que Palma está menos lejos de González Prada de lo que hasta ahora parece» (Mariátegui, 1979: 221). Mariátegui explica también que a Palma se le atribuyó el adjetivo de colonialista porque la mayoría de los críticos pensaron «en la divergencia personal entre Palma y González Prada; se ha alimentado, luego del contraste espiritual entre "palmistas y pradistas"» (Mariátegui, 1979: 220).

Uno de los más importantes momentos de la compleja relación entre el tradicionista y el autor de Páginas libres es también el episodio de la Biblioteca Nacional. El crítico literario detalla este episodio en su obra Don Manuel y cuenta que después del nombramiento de González Prada como director de la Biblioteca Nacional hubo reacciones agresivas en su contra y que incluso un grupo de intelectuales universitarios organizó una velada de homenaje a Palma frente a la casa de González Prada y él podía oír «las frases envenenadas de algunos estudiantes» (Sánchez, 1930: 233). En la edición Copé de 1986 de Obras de Manuel González Prada existen varias páginas dedicadas a la polémica de la Biblioteca Nacional. González Prada le reprocha al tradicionista haber estampado exageradamente sellos en los libros y «escribir tanto en antiportadas y colofones como en portadas y márgenes» (González Prada, 1986: 374) y también le recuerda a Palma que «un establecimiento público no es un bien personal ni una vinculación» (González Prada, 1986: 374). Otros autores recientes como Mónica Albizúrez Gil escriben sobre la intensidad de «la conocida polémica entre Manuel González Prada y Ricardo Palma, luego de la renuncia obligada de este como director de la Biblioteca Nacional y la subsiguiente aceptación del cargo por parte de Manuel González Prada» (Albizúrez Gil, 2008: 97).

En cuanto a la cercanía entre el tradicionista y González Prada, la influencia que ambos ejercieron en la obra de Clorinda Matto de Turner representa un punto común entre el autor de las Tradiciones peruanas y el de Páginas libres. Hay varios críticos literarios que dedican sus estudios a esta problemática, por ejemplo, «cómo la obra de Matto muestra el desplazamiento de la hegemonía cultural de Palma hacia González Prada» (Moreano, 2006: 251), como antes de que Clorinda Mato de Turner participara en el Círculo Literario, había recibido «la principal influencia literaria [...] de Ricardo Palma» (Kristal, 1991a: 125), como las novelas de Clorinda Matto «dieron vida literaria a la concepción política de González Prada sobre el indio» (Kristal, 1991b: 122), como «sin renunciar a Palma, la célebre escritora aceptó sutilmente aspectos de la doctrina social de González Prada» (Ward, 2010).

En su intento de librarse de la literatura anterior, González Prada consiguió ofrecer al pueblo peruano una obra que fomentara el interés de definir su propia identidad, utilizó la historia y el pasado de su país como instrumentos y herramientas de un trabajo que pretendía extender un velo literario sobre los hechos históricos más relevantes con el propósito de reivindicar el modo de ser del pueblo peruano. 


\section{3. «Indio-espectáculo» versus «indio-problema»}

La polémica entre las dos figuras peruanas más destacadas del siglo XIX va mucho más allá. Y así nos adentramos en la segunda parte del presente trabajo, la lucha por la obtención de derechos para la población indígena. Luis Alberto Sánchez comenta el distanciamiento producido entre el tradicionista y González Prada desde el punto de vista del tratamiento del problema del indígena: mientras Palma se limitaba al «indio-espectáculo» (Sánchez, 1929: 362), buscándolo para hablar de él en su obra, González Prada se detuvo en el «indio-problema» (Sánchez, 1929: 362), interviniendo contra los poderes constituidos para luchar por los derechos de la población indígena. González Prada fue promotor de la campaña Proindios (después de la guerra con Chile), fue el que afirmó que el indio era una raza social, no una raza biológica. Según el autor, indio era en el Perú el que no tenía nada y en cuanto tenía algo, blanqueaba. El blanco lo tenía todo. Esta era la situación del Perú de 1900. El escritor consiguió presentar la cuestión indígena como un problema estructural y relacionó la libertad con el progreso de su país, progreso que estaba en las manos de los políticos que, desde el punto de vista del autor, eran «malos, muy malos, tan malos que han hundido y seguirán hundiendo al país» (Haya de la Torre, 1985: 101). El pueblo del Perú era un pueblo desgraciado y la necesidad de independizarlo implicaba también libertad en el pensamiento de aquellos capaces de cambiar el rumbo del país hacia una nación que integrara a todos los ciudadanos y ofrecer derechos iguales para toda la población. Ese fue uno de los motivos que hizo que el autor no solo criticara al sistema político de su país, sino que también propusiera una literatura que ejerciera una crítica sociopolítica.

La falta de interés por la cuestión indígena en la época republicana demuestra, desde el punto de vista de González Prada, que «en la República se repiten con los indios las mismas iniquidades que se perpetraban en el Virreinato» con la diferencia de que «los españoles usaban la hipocresía de la religión» y sus contemporáneos «la hipocresía de la libertad» (González Prada, 1941: 117-118). Teniendo en cuenta que González Prada consideraba que la cuestión indígena debía ser «entendida y atendida» (Salvattecci, 1990: 421) porque representaba un problema que llevaba siglos sin resolverse, él aparece como «el apóstol rebelde que busca en el indio, en el provinciano, en el obrero, las mejores posibilidades para su patria» (Salvattecci, 1990: 12). González Prada se aproxima al problema de la estratificación de la sociedad peruana con miras «indigenistas» (Berg, 2006: 201) y en su obra encontramos «la primera formulación directa de la cuestión indígena como problema estructural» (Salazar Bondy, 1972).

El artículo «Nuestros indios» denuncia la explotación de la población indígena y la difícil situación en la que esta se hallaba por culpa del maltrato recibido después de la Conquista y durante el período colonial, causado por la falta de acceso a la educación y por falta de libertades. Según el autor, el nivel de vida de los indígenas era tan bajo que «la palabra de un español ante una corte equivalía a la de tres indios» (Ortega, 1978: 43). Esta situación los convirtió en «desheredados del espíritu» (Ortega, 1978: 37), por haberse alejado de sus creencias, sus tradiciones y su identidad.

En las Baladas peruanas de Manuel González Prada hallamos también referencias a la manera de ser de los incas, a su valentía, a su inocencia, a su deseo de libertad y también a la forma de vestirse. En «Los amancaes» el autor relata la inocencia de las jóvenes vírgenes engañadas por sus enamorados, que cautivaban con hechizos sus frágiles corazones:

Siete Príncipes hermanos

de invencible y dulce voz, 
cautivaron con su hechizo

nuestro frágil corazón

(González Prada, 2004: 35).

La importancia de la libertad llevaba a veces a los incas a sacrificios supremos. En la balada «El cacique filicida», el autor relata la historia de un padre que prefirió matar a su hijo en vez de dejarlo vivir una vida en esclavitud o trabajando sin cesar en las minas. La misma idea de preferir la muerte ante la posesión de los conquistadores la encontramos en «La hija del curaca», donde González Prada narra la consolación de un padre ante la muerte de su hija:

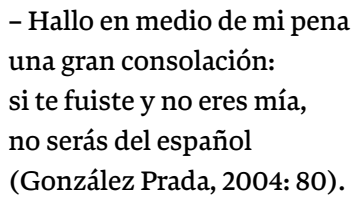

En Nuevas páginas libres González Prada utiliza el símbolo del cóndor para hacer referencia a las batallas de Junín y Ayacucho y presenta una posible alternativa en el caso en que el Perú no hubiera obtenido su independencia: «Si los españoles hubieran triunfado en Junín y Ayacucho, tendríamos leones de Iberia desgarrando a cóndores de los Andes, en lugar de Diosas de la Libertad pisando la garganta de la tiranía» (González Prada 1937, 73).

\section{Ruptura con las lacras del periodo colonial prolongadas hasta la República}

Después de obtener la independencia, el Perú fue uno de los países hispanoamericanos que retrocedió más en su feudalismo y «cayó en un letargo clerical, militarista y de explotación racial que ahogó todo esfuerzo de progreso» (Rovira, 1993: 12). La Unión Nacional fue el partido fundado por Manuel González Prada en mayo de 1891 y era «un partido federalista, nacionalista, indigenista, laicista, con inclinaciones al anarquismo» (Prada, 1985: 210). Por lo tanto, el interés de González Prada por la mejora de la situación de la población indígena representaba incluso una de las metas de su partido. Uno de los puntos del programa del partido era «la devolución de las tierras usurpadas a las comunidades indígenas» (Basadre, 1949: 293) y en la visión de González Prada está presente «la indagación ante el sufrimiento de los explotados y la injusticia flagrante que es la sociedad peruana» (Loayza, 1990: 13).

En Prosa menuda González Prada expresa su opinión sobre los criollos que nacieron como «una especie de generación espontánea» (González Prada, 1941: 176) y que «brotaron de la podre colonial como los hongos germinan en el estercolero» (González Prada, 1941: 176). Y también habla de las huellas de la herencia hispánica desde un punto de vista moral: «Entre nosotros, como buenos descendientes de españoles, el mal no ha desaparecido, aunque se manifieste con mayor o menor intensidad, según las épocas y las circunstancias» (González Prada, 1941: 60). En la misma obra hallamos referencia a la Conquista y a la inferioridad de los españoles frente a los indígenas para después encontrar una comparación con la situación presente de la sociedad y clase política peruanas de la época de González Prada:

¿Quiénes merecen el título de salvajes: los indios bravos que habitan en los bosques o los blancos y mestizos que van a civilizarles? Cuando los españoles vinieron a sembrar la civilización entre 
los Incas, resultó que los súbditos de Carlos $\mathrm{V}$ eran moralmente inferiores a los descendientes de Manco Cápac: hoy está sucediendo que nuestros emisarios y colonos en el Madre de Dios se muestran más salvajes que los Guarayos y los Campas (González Prada, 1941: 112-113).

González Prada tocó el tema de la crítica hacia la Conquista y el período de la Colonia también en Páginas libres: «Nada igual ocurre en el Perú. Aquí no existe nobleza: y a la idea de linaje puro, sonríe maliciosamente el que sabe cómo vivieron las familias nobles del Perú en el tiempo del Coloniaje, señaladamente en el siglo XVII» (González Prada, 1985: 28). El conflicto con Chile despertó en el autor recuerdos sobre la época de la Conquista y la Colonia y las consecuencias hacia la población indígena. Desde su punto de vista, la historia es cruel con los vencidos y enaltece a los vencedores, a pesar de los medios a través de los cuales se obtuvo la victoria:

Digan lo que digan ilusos y sentimentales, quien vence, vence. El vencedor, aunque pulverice al vencido y cometa delitos de lesa humanidad, deslumbra y seduce al mundo. En la mascarada de la Historia, todo crimen con la aureola del buen éxito se conquista el nombre de virtud.

Si algo cuesta salir vencido, respondan los habitantes de Iquique y Tarapacá, condenados a vivir de huéspedes en su propia casa; respondan los de Arica y Tacna, destinados a esperar dudoso rescate, como navegantes cautivos por piratas argelinos (González Prada 1985, 55).

Al hablar González Prada de oprimidos, no podemos dejar de pensar en los indígenas y cuando se refiere a la relación vencido-vencedora, oprimido-opresora, no podemos pensar más que en lo que pasó con la población indígena y los colonizadores:

[...] respetamos hoy como sagradas las abominaciones que nosotros mismos consagramos ayer, veremos que nos conducimos como el niño que vuelve sus espaldas a la bujía y se espanta con la gigantesca proyección de su propia sombra.

Esa palabra resignación, inventada por los astutos que gozan, para encadenar el brazo de los inocentes que sufren iniquidades y atropellos, debe desaparecer de todos los labios, porque resuena como sinónimo de ultraje en el opresor, de cobardía en el oprimido. Quitemos al poderoso algo de su poder, al rico algo de su riqueza, y veremos si conocen y preconizan la resignación (González Prada 1985, 103-104).

Según el autor, la prolongación de la opresión del sistema colonial se nota durante la República en los pueblos «donde no existe más ley que la obtusa voluntad de un prefecto, de un subprefecto, de un gobernador o de un comandante de partida» (González Prada, 1985: 212).

Prada consideraba que la Independencia no trajo consigo la libertad absoluta y parte de las leyes impuestas por los gobernantes hacía que continuara la situación que había durante el período colonial: «Lo último significa el retroceso a la época de la dominación española [...]» (González Prada, 1985: 328).

Además, volviendo hacia el pasado, González Prada llamaba la atención sobre las acciones inhumanas de aquellos conquistadores que se aprovecharon de la ingenuidad de la población indígena y remitía a Bartolomé de las Casas:

Primero los Conquistadores, en seguida sus descendientes, formaron en los países de América un elemento étnico bastante poderoso para subyugar y explotar a los indígenas. Aunque se tache de exagerables las afirmaciones de Las Casas, no puede negarse que merced a la avarienta crueldad de 
los explotadores, en algunos pueblos americanos el elemento débil se halla próximo a extinguirse. Las hormigas que domestican pulgones para ordeñarlas, no imitan la imprevisión del blanco, no destruyen a su animal productivo (González Prada 1985, 335-336).

De las afirmaciones del autor destaca la idea de que las altas autoridades españolas conocían los problemas existentes en América en general, y en el Perú en particular, que Las Casas denunció y tomaban medidas superficiales para acabar con el maltrato de la población indígena:

Los Virreyes del Perú no cesaron de condenar los atropellos ni ahorraron diligencias para lograr la conservación, buen tratamiento y alivio de los Indios; los Reyes de España, cediendo a la conmiseración de sus nobles y católicas almas, concibieron medidas humanitarias o secundaron las iniciadas por los Virreyes. Sobraron los buenos propósitos en las Reales Cédulas. Ignoramos si las Leyes de Indias forman una pirámide tan elevada como el Chimborazo; pero sabemos que el mal continuaba lo mismo, aunque algunas veces hubo castigos ejemplares. Y no podía suceder de otro modo: oficialmente se ordenaba la explotación del vencido y se pedía humanidad y justicia a los ejecutores de la explotación; se pretendía que humanamente se cometiera iniquidades o equitativamente se consumara injusticias. Para extirpar los abusos, habría sido necesario abolir los repartimientos y las mitas, en dos palabras, cambiar todo el régimen colonial. Sin las faenas del indio americano, se habrían vaciado las arcas del tesoro español. Los caudales enviados de las colonias a la Metrópoli no eran más que sangre y lágrimas convertidas en oro (González Prada, 1985: 337).

El autor relata que la riqueza traída desde el Perú a España supuso el sufrimiento de los indígenas a través de trabajo difícil, pérdidas de vidas por no revelar el secreto de los tesoros escondidos y acciones crueles por parte de aquellos cuyo propósito era enriquecerse sin pensar en los sufrimientos causados. González Prada afirma que la Conquista representó pérdida de vidas y sumisión ante la corona española: «Sólo supiste, ioh nebulosa España! / Verter la sangre y adorar la fuerza» (González Prada, 1979: 23).

Manuel González Prada muestra la realidad de la Conquista y del período colonial que, la mayoría de las veces, según los ejemplos ofrecidos extraídos de sus obras, representó la humillación de la población indígena obligada a aguantar explotaciones y abusos de todo tipo. Las Baladas peruanas son una parte de la obra de Manuel González Prada que representa un testimonio del sufrimiento de la población indígena sometida a injusticias y crueldades y por eso la crítica considera que «con Prada nace la poesía indigenista» (Sánchez, 1977: 45). Mientras su estancia en la hacienda de Mala entra en contacto directo con la población indígena y en estas circunstancias «contempla al indio, sintiendo en carne propia su dolor silencioso y sin esperanza; comprueba la situación inhumana en que se halla» (Guerra M., 1964: 16-17) para que después su obra refleje la rebeldía que sentía ante la realidad que no era lo deseable. González Prada «consideró el problema indígena como parte integrante e inseparable del problema nacional» (Chang Rodríguez, 1976: 242).

El autor critica no solo el periodo colonial, sino también la sociedad peruana del siglo XIX porque se considera responsable del porvenir de las generaciones futuras, vive proyectado hacia el futuro, pero en una constante inconformidad en cuanto al presente. Pero aun así en el poema «Tiempos pasados» pide que le devuelvan su pasado (González Prada, 1973:, s. p.). Evidentemente el autor está relacionado, como todos los hombres, con las tres referencias temporales fundamentales en la vida, pasado, presente y futuro. Tal como habíamos mencionado anteriormente, según el escritor, una vez llegada la Independencia siguió también el orden colonial porque en el Perú 
«no se habían producido alteraciones sustanciales» y la consecuencia fue que «el indígena, y por tanto las raíces culturales del Perú prehispánico, seguían quedando al margen, excluidos y relegados al sórdido papel que el orden colonial les había asignado» (Valero Juan, 2005: 352).

La corriente criollista e indigenista nació, pasando de «mero alarde ornamental» (Sánchez, 1973: 28) como en el caso de los románticos, con los «nuevos hombres del 70» (Sánchez, 1973: 28), que realzaban el valor de la provincia y de los pobladores de la zona para oponerse a la política centralista de España, la Colonia y el clero. Las luchas intestinas e internacionales de 186484 fueron el estímulo que llevó al perfilamiento de las nacionalidades hispanoamericanas y el comienzo del brote del «autoctonismo» (Sánchez, 1973: 28), donde una figura importante es la de Manuel González Prada.

\section{Conclusiones}

Según Luis Alberto Sánchez y el hijo del autor, Alfredo González Prada, en torno al autor «se reunió la generación de la posguerra. Acaudilló el movimiento juvenil contra el clasicismo, contra el españolismo, contra el clericalismo, contra la oligarquía, contra la tradición colonialista» (González Prada, 1948: 7). Este último decía que su padre no fue un rebelde sino un inconforme, como la mayoría de los grandes escritores, y «que combatió con una poca peruana persistencia y furia contra toda corrupción política, hipocresía religiosa e injusticia social» (González Prada, 1946: 250), que, según nuestra opinión, representa su lucha en contra de las lacras del sistema colonial prolongado hasta los tiempos de González Prada, tiempos que el autor quería cambiar para que las generaciones futuras tuvieran un presente mejor. Y sus escritos tuvieron eco a lo largo de los siglos en la conciencia de los peruanos, porque escribió su obra con la intención de desafiar el tiempo.

A través de una crítica constante, Manuel González Prada mostró «una preocupación férrea por los derechos humanos, la libertad y la justicia» (Ward, 2009: 188) porque, según sus obras, la mayoría de las veces las víctimas de las decisiones políticas y de las iniquidades cometidas por las autoridades eran los indígenas. La falta de derechos y de dignidad, la falta de libertad real, llevaba a la supresión de cualquier sentimiento nacional. Lo que González Prada quiso obtener fue exactamente despertar en las mentes y en los corazones de los peruanos la necesidad de integrar en la nación a una parte olvidada por la historia del país y también por la clase política y por la sociedad, que ignoraba los derechos y la cultura de la población incaica. 


\section{Bibliografía}

ע ALbizúrez GIL, Mónica (2008). «Reconsideraciones sobre el asalto de Manuel González Prada a la Biblioteca Nacional de Lima». Revista de Crítica Literaria Latinoamericana, 34.68, pp. 97-119.

У BASADRE, Jorge (1949). Historia de la República del Perú. Tomo II. Lima: Editorial Cultura Antártica.

У BERG, Walter Bruno (2006). «Manuel González Prada y el otro fin de siglo». In: Isabelle Tauzin, Manuel González Prada: escritor de dos mundos. Lima: Tarea Asociación Gráfica Educativa, pp. 199-211.

У CHANG-RODRÍGUez, Eugenio (1976). «El ensayo de Manuel González Prada». Revista Iberoamericana 42, pp. 239-249. https://doi.org/10.5195/REVIBEROAMER.1976.3106 GONZÁLEZ PRADA, Manuel (1937). Nuevas páginas libres. Santiago de Chile: Ediciones Ercilla. GONZÁLEZ PRADA, Manuel (1941). Prosa menuda. Buenos Aires: Ediciones Imán. GONZÁLEZ PRADA, Alfredo (1946). Redes para captar la nube. Lima: Editorial PTCM.

У GONZÁLEZ PRADA, Manuel (1948). Anarquía. 4ª edición. Lima: Editorial PTCM, 1948. In: Obras completas de González-Prada. Tomo III. GONZÁlez PRADA, Manuel (1973). Poemas desconocidos. Lima: Ediciones de la Clepsidra. cervantesvirtual.com/obra/baladas/ [17/09/2019]. GUERRA M., Luis Felipe (1964). Gonzales Prada. Lima: Editorial Universitaria. HAYA DE LA TORRE, Víctor Raúl (1985). «Mis recuerdos de González Prada». In: Willy F. Pinto G. Manuel González Prada: profeta olvidado. Lima: Editorial Cibeles, pp. 89-104.

๖ KRISTAL, Efraín (1991a). «La dimensión política del indigenismo de Clorinda Matto de Turner». In: Efraín Kristal. Una visión urbana de los Andes. Lima: Instituto de Apoyo Agrario, pp. 123-153. KRISTAL, Efraín (1991b). «González Prada y la élite industrial». In: Efraín Kristal. Una visión urbana de los Andes. Lima: Instituto de Apoyo Agrario, pp. 95-122.

$\checkmark$ LOAYZA, Luis (1990). Sobre el novecientos. Lima: Mosca Azul Editores.

ע MARIÁTEGUi, José Carlos (1985). «Conversación con don Manuel González Prada». In: Willy F. Pinto G. Manuel González Prada: profeta olvidado. Lima: Editorial Cibeles, pp 49-64. MARIÁtegui, José Carlos (1979). «Ricardo Palma, Lima y la Colonia». In: José Carlos Mariátegui. Siete ensayos de interpretación de la realidad peruana. México: Ediciones Era, pp. 218-227.

У MOREAno, Cecilia (2006). «"El pesado casco de Minerva”: influencia de Palma y González Prada en la obra de Clorinda Matto de Turner». In: Isabelle Tauzin Castellanos. Manuel González Prada: escritor de dos mundos. Lima: Tarea Asociación Gráfica Educativa, pp. 251-277. ORTEGA, Julio (1978). La cultura peruana. Experiencia y conciencia. México: Fondo de Cultura Económica. PINTO G., Willy F. (1985). Manuel González Prada: profeta olvidado. Lima: Editorial Cibeles.

PORRAS BARRENECHEA, Raúl (1969). El sentido tradicional en la literatura peruana. Lima: Instituto Raúl Porras Barrenechea.

У RovirA, Catherine (1993). Semblanza y circunstancia de Manuel González Prada. Miami: Ediciones Universal.

ע SAlAZAR Bondy, Augusto (1972). «Prólogo». In: Manuel González Prada. Horas de lucha. Lima: Editorial Universo, sin p.

ע SAlvattecci, García (1990). Visión de un apóstol. Pensamiento del Maestro González Prada. Lima: Emisa Editores.

У SÁNCHEZ, Luis Alberto (1929). «Perfil de lo romántico e indagación del “lejanismo”». Mercurio Peruano, 29, p. 362.

$\checkmark$ SÁNCHEZ, Luis Alberto (1930). Don Manuel. Lima: Casa Editorial E. Rosay.

У SÁNCHEZ, Luis Alberto (1973). Balance y liquidación del Novecientos. ¿Tuvimos maestros en nuestra América? Lima: Editorial Universo. 
У SÁNCHEZ, Luis Alberto (1976). Mito y realidad de González Prada. Lima: P. L. Villanueva.

У SÁNCHEZ, Luis Alberto (1977). Nuestras vidas son los ríos... (Historia y leyenda de los González Prada). Lima: Universidad Nacional de San Marcos.

У VALERo jUAN, Eva María (2005). «El costumbrismo y la bohemia romántica en el Perú: un tránsito hacia la “tradición”». Anales de Literatura Española, 18, pp. 351-366. https://doi.org/10.14198/ALEUA.2005.18.26

$\checkmark \quad$ WARD, Thomas (2009). «Feminismo liberal vs. anarquismo radical: obreras y obreros en Matto de Turner y González Prada, 1904-05». A Contracorriente, ${ }^{\circ}$ 1, vol. 7, pp. 188-210.

$\checkmark \quad$ WARD, Thomas (2010). «Rumbos hacia una teoría literaria peruana comprometida: Matto de Turner, Cabello de Carbonera, y González Prada». Alicante: Biblioteca Virtual Miguel de Cervantes. http://www. cervantesvirtual.com/obra-visor/rumbos-hacia-una-teoria-literaria-peruana-comprometida-matto-de-turner-cabello-de-carbonera-y-gonzalez-prada/html/347896e9-2300-4af5-835c-89d4af42fb72_8. html\#I_0_[17/09/2019].

\author{
Aura Cristina Bunoro \\ Universitatea din București \\ Facultatea de Limbi și Literaturi Străine \\ Departamentul de Limbi și Literaturi Romanice, Clasice și Neogreacă \\ Str. Edgar Quinet nr. 5-7 \\ cod 010017, sector 1 \\ BUCUREŞTI \\ România
}

